\title{
Genetic Screening
}

National Cancer Institute

\section{Source}

National Cancer Institute. Genetic Screening. NCI Thesaurus. Code C92803.

Testing to determine if there is a predisposition or indication of a possible genetic or a chromosomal abnormality. 